\title{
Involvement of organic cation transporter-3 and plasma membrane monoamine transporter in serotonin uptake in human brain vascular smooth muscle cells
}

\author{
Rachel W. S. Li ${ }^{1}$, Cui Yang ${ }^{1}$, Y. W. Kwan' ${ }^{2}$, S. W. Chan ${ }^{3}$, Simon M. Y. Lee ${ }^{4}$ and George P. H. Leung ${ }^{\text {* }}$ \\ 1 Department of Pharmacology and Pharmacy, The University of Hong Kong, Pokfulam, Hong Kong \\ 2 School of Biomedical Sciences, The Chinese University of Hong Kong, Shatin, Hong Kong \\ ${ }^{3}$ State Key Laboratory of Chinese Medicine and Molecular Pharmacology, Department of Applied Biology and Chemical Technology, The Hong Kong Polytechnic \\ University, Hung Hom, Hong Kong \\ ${ }^{4}$ Institute of Chinese Medical Science, The University of Macau, Macau, China
}

\section{Edited by:}

Ikunobu Muramatsu, University of Fukui School of Medicine, Japan

Reviewed by:

Jian-Dong Luo, Second Military Medical University, China

Naohiko Anzai, Dokkyo Medical

University School of Medicine, Japan

\section{${ }^{*}$ Correspondence:}

George P. H. Leung, Department of Pharmacology and Pharmacy, The University of Hong Kong, 21 Sassoon Road, Pokfulam, Hong Kong. e-mail: gphleung@hku.hk
The serotonin $(5-\mathrm{HT})$ uptake system is supposed to play a crucial part in vascular functions by "fine-tuning" the local concentration of $5-\mathrm{HT}$ in the vicinity of $5-\mathrm{HT}_{2}$ receptors in vascular smooth muscle cells. In this study, the mechanism of $5-\mathrm{HT}$ uptake in human brain vascular smooth muscle cells (HBVSMCs) was investigated. [ $\left.{ }^{3} \mathrm{H}\right] 5-\mathrm{HT}$ uptake in HBVSMCs was $\mathrm{Na}^{+}$-independent. Kinetic analyses of $\left.{ }^{3} \mathrm{H}\right] 5-\mathrm{HT}$ uptake in HBVSMCs revealed a $K_{m}$ of $50.36 \pm 10.2 \mathrm{mM}$ and a $V_{\max }$ of $1033.61 \pm 98.86 \mathrm{pmol} / \mathrm{mg}$ protein/min. The specific serotonin re-uptake transporter (SERT) inhibitor citalopram, the specific norepinephrine transporter (NET) inhibitor desipramine, and the dopamine transporter (DAT) inhibitor GBR12935 inhibited $5-H T$ uptake in HBVSMCs with $I_{50}$ values of $97.03 \pm 40.10,10.49 \pm 5.98$, and $2.80 \pm 1.04 \mu \mathrm{M}$, respectively. These $\mathrm{IC}_{50}$ values were 100 -fold higher than data reported by other authors, suggesting that those inhibitors were not blocking their corresponding transporters. Reverse transcription-polymerase chain reaction results demonstrated the presence of mRNA for organic cation transporter (OCT)-3 and plasma membrane monoamine transporter (PMAT), but the absence of OCT-1, OCT-2, SERT, NET, and DAT. siRNA knockdown of OCT-3 and PMAT specifically attenuated 5-HT uptake in HBVSMCs. It is concluded that $5-\mathrm{HT}$ uptake in HBVSMCs was mediated predominantly by a low-affinity and $\mathrm{Na}^{+}$-independent mechanism. The most probable candidates are OCT-3 and PMAT, but not the SERT.

Keywords: serotonin, organic cation transporter, monoamine transporter, vascular smooth muscle cells

\section{INTRODUCTION}

Serotonin [5-hydroxytryptamine (5-HT)] is not only a neurotransmitter in the central nervous system and digestive tract, but also a potent vasoconstrictor. In the cardiovascular system, 5-HT is mainly stored in platelets, thereby maintaining a low level of free-circulating 5-HT. 5-HT is released during platelet aggregation. The released 5-HT feeds back on the platelets to amplify the aggregation process and causes the contraction of vascular smooth muscle cells through the stimulation of $5-\mathrm{HT}_{2}$ receptors (Vanhoutte, 1990).

Several studies have suggested that 5-HT may be involved in vascular diseases such as hypertension. For instance, arterial contraction to 5-HT is profoundly enhanced in hypertension in animals and humans (Wyse, 1984; Dohi and Lüscher, 1991; HutriKähönen et al., 1999). Also, an increased plasma level of 5-HT has been measured in various models of hypertension (Soares-da-Silva et al., 1995; Krygicz et al., 1996).

Arteries can take up 5-HT. This mechanism is crucial to the vascular functions of 5-HT because it "fine-tunes" the availability of 5-HT at its cognate receptors. The action of 5-HT is supposed to be terminated after it is removed from its site of action and is taken up into the cytosol of vascular cells, where 5-HT is eventually metabolized by monoamine oxidase-A ( $\mathrm{Ni}$ et al., 2004). Interestingly, two research teams have reported that the uptake of 5-HT is a prerequisite for the mitogenic effect of 5-HT on pulmonary arterial smooth muscle (Lee et al., 1991; Eddahibi et al., 1999). Being a protonated molecule, 5-HT cannot diffuse across the lipid bilayer of the cell membrane under physiological conditions. Therefore, transporter-mediated mechanisms play a key part in 5-HT uptake. Similar to neurons, the smooth muscle cells of the aorta contain a specific serotonin re-uptake transporter (SERT; Ni et al., 2004). 5-HT uptake in the rat aorta is inhibited by the SERT inhibitors fluoxetine and fluvoxamine (Ni et al., 2004). In addition, a significant part of 5-HT is taken up by rat extracerebral arteries via a high-affinity transporter, which is also consistent to the characteristics of SERT (Amenta et al., 1985). Moreover, the contracting effect of 5-HT on the aorta can be potentiated by SERT inhibitors (Ni et al., 2004). The SERT may also contribute to the regulation of vascular contractility under pathophysiological conditions. For instance, the SERT in pulmonary vascular smooth muscle is up-regulated by hypoxia (Eddahibi et al., 1999; Wanstall et al., 2003) and pulmonary hypertension (Eddahibi et al., 
2001). Besides, SERT activities in deoxycorticosterone acetate saltand $N_{\omega}$-nitro-L-arginine-induced hypertensive rats are lower than those in normal rats (Ni et al., 2006).

Although 5-HT can be taken up by blood vessels, many problems have not been resolved. First, 5-HT-induced vasoconstriction in the main pulmonary artery and mesenteric artery cannot be enhanced by SERT inhibitors (Wanstall et al., 2003). Second, 5HT uptake is reduced, but not abolished, in the carotid artery, mesenteric artery, and aorta of SERT-knockout rats compared with wild-type rats (Linder et al., 2008a). Although SERT protein is expressed in veins, it is not functional, since the 5-HT uptake in vein cannot be significantly inhibited by classic SERT inhibitors (Linder et al., 2008b). Therefore, a non-SERT-dependent mechanism may be present which may make contributions to 5-HT uptake in certain vascular beds. It is particularly of interest to study the 5-HT uptake mechanism in cerebral arteries since 5HT is considered to be involved in the regulation of the cerebral circulation, and is implicated in the etiology of cerebrovascular diseases such as migraine, vasospasm due to subarachnoid hemorrhage, and stroke (Parsons, 1991). Studies have also shown that the 5-HT-induced contraction is enhanced in the basilar arteries of hypertensive rats (Nishimura, 1996). Therefore, we sought to characterize the 5-HT uptake mechanism in human brain vascular smooth muscle cells (HBVSMCs) in the present study.

\section{MATERIALS AND METHODS CULTURE OF HBVSMCS}

Primary culture of HBVSMCs were obtained from ScienCell Research Laboratories (Carlsbad, CA, USA) and cultured in the medium supplied by the same company, at $37^{\circ} \mathrm{C}$ in an atmosphere of $95 \%$ air and $5 \% \mathrm{CO}_{2}$.

\section{5-HT UPTAKE}

Experiments were carried out in HEPES-buffered Ringer's solution containing (in $\mathrm{mM}$ ): $135 \mathrm{NaCl} ; 5 \mathrm{KCl} ; 3.33 \mathrm{NaH}_{2} \mathrm{PO}_{4}$; $0.83 \mathrm{Na}_{2} \mathrm{HPO}_{4} ; 1.0 \mathrm{CaCl}_{2} ; 1.0 \mathrm{MgCl}_{2} ; 5 \mathrm{HEPES}$; and $10 \mathrm{D}$ glucose (adjusted to $\mathrm{pH} 7.4$ or other $\mathrm{pH}$ as specified in the figures). Experiments were also carried out in $\mathrm{Na}^{+}$-free buffer containing (in $\mathrm{mM}$ ): $140 \mathrm{~N}$-methyl-D-glucamine (NMDG); 5 HEPES; $5 \mathrm{KH}_{2} \mathrm{PO}_{4} ; 1.0 \mathrm{CaCl}_{2} ; 1.0 \mathrm{MgCl}_{2}$; and $10 \mathrm{D}$-glucose ( $\mathrm{pH} 7.4)$.

Confluent monolayers of cells in 24-well plates were washed thrice in HEPES-buffered Ringer solution. Cells were pretreated with the monoamine oxidase-A inhibitor clorgyline $(10 \mu \mathrm{M})$ for $10 \mathrm{~min}$ and $300 \mu \mathrm{L}$ of Ringer solution containing $\left[{ }^{3} \mathrm{H}\right] 5-\mathrm{HT}$ $(1 \mu \mathrm{M}, 2 \mu \mathrm{Ci} / \mathrm{mL})$ was then added to each well for $30 \mathrm{~min}$. To determine the passive uptake of 5-HT, monolayers of cells were incubated in buffer containing $\left[{ }^{3} \mathrm{H}\right] 5$-HT in the presence of excess non-radiolabeled 5-HT ( $1 \mathrm{mM})$. Plates were then rapidly washed three times with ice-cold phosphate-buffered saline (PBS) containing (in mM): $137 \mathrm{NaCl}, 2.68 \mathrm{KCl}, 1.47 \mathrm{KH}_{2} \mathrm{PO}_{4}$, and $8.1 \mathrm{Na}_{2} \mathrm{HPO}_{4}$ ( $\mathrm{pH}$ 7.4). Cells were solubilized in $0.5 \mathrm{~mL}$ of $5 \%(\mathrm{v} / \mathrm{v})$ Triton X100 . The radioactivity was measured by a $\beta$-scintillation counter. Protein content was determined by spectrophotometric means using a commercial bicinchoninic acid assay (Pierce Biochemicals, Rockford, IL, USA).

\section{RNA ISOLATION AND REVERSE TRANSCRIPTION-POLYMERASE CHAIN REACTION}

Total RNA was isolated from HBVSMCs using TRIzol reagent (Invitrogen, Carlsbad, CA, USA). Two micrograms of total RNA were used for first-strand cDNA synthesis using random hexamer primers and Superscript II RNase $\mathrm{H}^{-}$Reverse Transcriptase (SuperScript Pre-amplification System, Invitrogen). The resulting first-strand cDNA was directly used for PCR amplification. The primers for amplifying various transporters have been used in other studies (Martel et al., 2003; Tahara et al., 2006; Zhang et al., 2006) and their sequences are listed in Table 1. PCR amplification was carried out using PCR SuperMix (Invitrogen) with the following parameters: denaturation at $94^{\circ} \mathrm{C}$ for $30 \mathrm{~s}$, annealing at $55^{\circ} \mathrm{C}$ for $30 \mathrm{~s}$, and extension at $68^{\circ} \mathrm{C}$ for $45 \mathrm{~s}$. Thirty cycles were completed. This was followed by a final extension at $72^{\circ} \mathrm{C}$ for $10 \mathrm{~min}$. PCR products were analyzed by $1 \%$ agarose gel electrophoresis and visualized by staining with ethidium bromide. To semi-quantify the PCR products of nucleoside transporters, the optical density values of protein bands were normalized to those of $\beta$-actin.

\section{WESTERN BLOTTING}

Human brain vascular smooth muscle cells were grown to confluence on 10-cm Petri dishes. The cells were washed three times with ice-cold PBS, scraped in $2 \mathrm{~mL}$ of $5 \mathrm{mM}$ sodium phosphate, $\mathrm{pH} 8$, with protease inhibitor cocktail [Sigma, St. Louis, MO; $1: 100(\mathrm{v} / \mathrm{v})]$. Cells were sonicated briefly and centrifuged at 3,000 $\mathrm{g}$ for $10 \mathrm{~min}$ to remove nuclei and unbroken cells. The resulting supernatant was centrifuged at $30,000 \mathrm{~g}$ for $30 \mathrm{~min}$ to pellet the crude microsomal membranes, which was resuspended in $5 \mathrm{mM}$ sodium phosphate. The crude membranes were then resolved on $9 \%(\mathrm{w} / \mathrm{v})$ SDS-polyacrylamide gels and electrotransferred onto nitrocellulose membranes. After blocking with 5\% (w/v) nonfat dry milk in PBS overnight at $4^{\circ} \mathrm{C}$, nitrocellulose membranes were incubated with the anti-organic cation transporter (OCT)-3 or anti-plasma membrane monoamine transporter (PMAT) antibody [1:100 (v/v) dilution in blocking solution], at room temperature for $2 \mathrm{~h}$. Nitrocellulose membranes were then washed extensively with $0.02 \%(\mathrm{v} / \mathrm{v})$ Triton X-100 in PBS. After washing, the membranes were incubated with the horseradish-conjugated goat anti-rabbit secondary antibody $[1: 5000(\mathrm{v} / \mathrm{v})$ dilution in blocking solution] at room temperature for $2 \mathrm{~h}$. Excess secondary antibody was again washed, and the bound secondary antibody was detected by enhanced chemiluminescence (Western Blot Chemiluminescence Reagent Plus; NEN Life Science Products, Boston, MA, USA). Protein expression of $\beta$-actin was similarly detected with the monoclonal mouse anti-actin antibody (Chemicon, Temecula, CA, USA). The molecular size of OCT-3, PMAT, and $\beta$-actin are 62,58 , and $42 \mathrm{kDa}$, respectively. Optical density values of OCT-3 and PMAT bands were normalized to those of $\beta$-actin.

\section{SIRNA KNOCKDOWN OF OCT-3 AND PMAT}

Human brain vascular smooth muscle cells were transiently transfected with siRNA specific for OCT-3 and PMAT (Qiagen Incorporated, Valencia, CA, USA) for 10-12 h with RNAifect Transfection Reagent (Qiagen), according to manufacturer's instructions. HBVSMCs were then further cultured for 24-48 h before used for mRNA determinations and 5-HT uptake study. 
Table 1 | Oligonucleotide sequence of the primers used for RT-PCR.

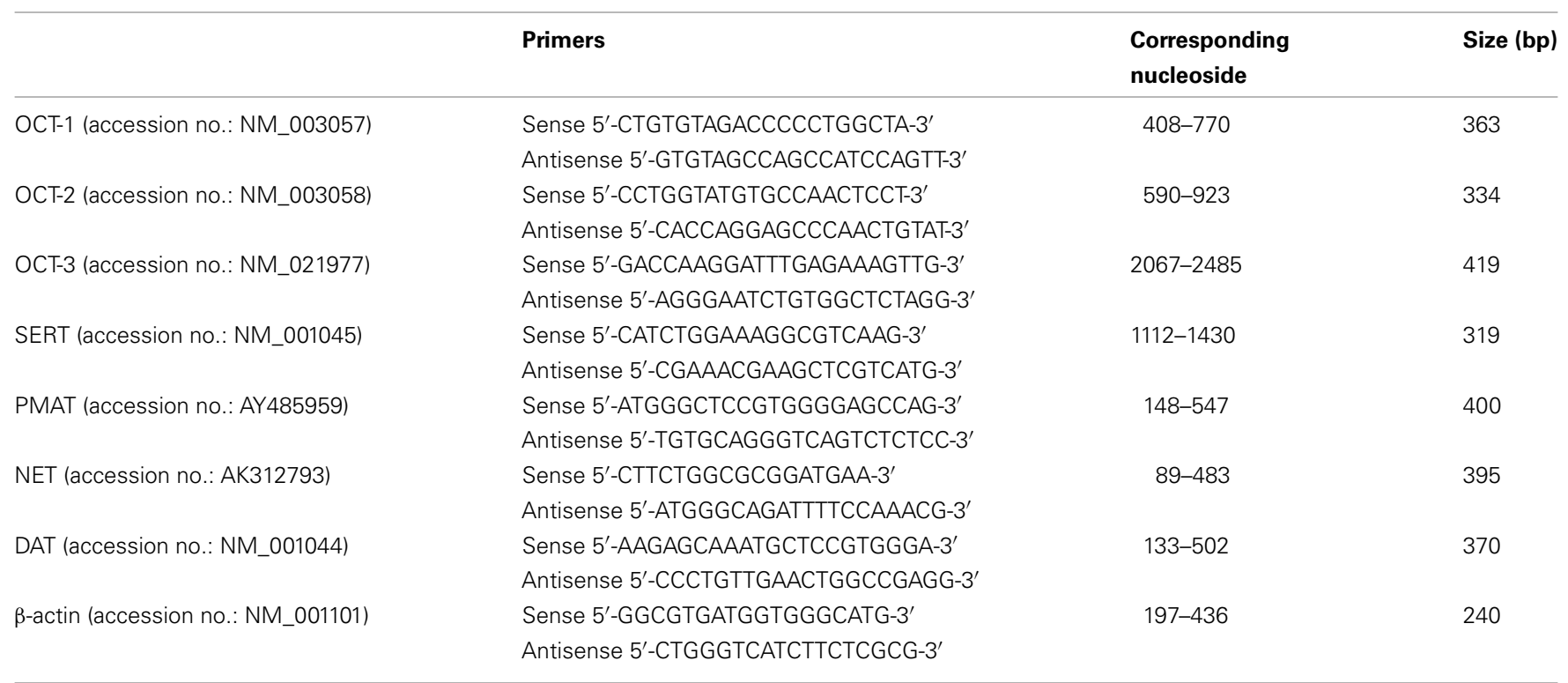

\section{MATERIALS}

$\left[{ }^{3} \mathrm{H}\right] 5-\mathrm{HT}$ was purchased from Moravek Biochemicals (Brea, CA, USA). All antibodies were purchased from Abcam (Cambridge, UK). Primers for PCR were bought from Invitrogen (CA, USA). Other chemicals were purchased from Sigma-Aldrich (St. Louis, MO, USA).

\section{STATISTICAL ANALYSES}

Data are means \pm SEM and were obtained from at least three independent experiments. Statistical analyses of the data were carried out using the Student's $t$-test or ANOVA (one-way and two-way), if appropriate. $P<0.05$ was considered significant.

\section{RESULTS}

\section{TIME-COURSE AND KINETICS OF 5-HT UPTAKE IN HBVSMCs}

5-HT uptake was measured in HBVSMCs after 0, 5, 10, and $30 \mathrm{~min}$ of incubation in $\left[{ }^{3} \mathrm{H}\right] 5-\mathrm{HT}(1 \mu \mathrm{M})$. Figure 1 shows that the uptake of 5-HT into HBVSMCs increased with time. There was no difference between $\mathrm{Na}^{+}$-dependent and $\mathrm{Na}^{+}$-independent uptake of $\left[{ }^{3} \mathrm{H}\right] 5-\mathrm{HT}$. The kinetic parameters of 5 -HT uptake were analyzed following a $30-\mathrm{min}$ incubation in $\left[{ }^{3} \mathrm{H}\right] 5-\mathrm{HT}$ at various concentrations $(0.1 \mu \mathrm{M}$ to $50 \mathrm{mM})$. The rate of $5-\mathrm{HT}$ uptake increased with increasing 5 -HT concentration and yielded typical saturation kinetics (Figure 2 ). The estimated $K_{\mathrm{m}}$ of 5HT uptake was $50.36 \pm 10.2 \mathrm{mM}$ and the estimated $V_{\max }$ was $1033.61 \pm 98.86 \mathrm{pmol} / \mathrm{mg}$ protein $/ \mathrm{min}$.

\section{EFFECT OF PHARMACOLOGICAL INHIBITORS ON 5-HT UPTAKE IN HBVSMCs}

To examine which type of transporters were responsible for 5-HT uptake in HBVSMCs, the effects of various inhibitors was studied. Citalopram (a specific SERT inhibitor), desipramine (a specific norepinephrine transporter (NET) inhibitor), and GBR12935 (a specific dopamine transporter (DAT) inhibitor) completely inhibited 5-HT uptake in HBVSMCs with $\mathrm{IC}_{50}$ values of $97.03 \pm 40.10$,

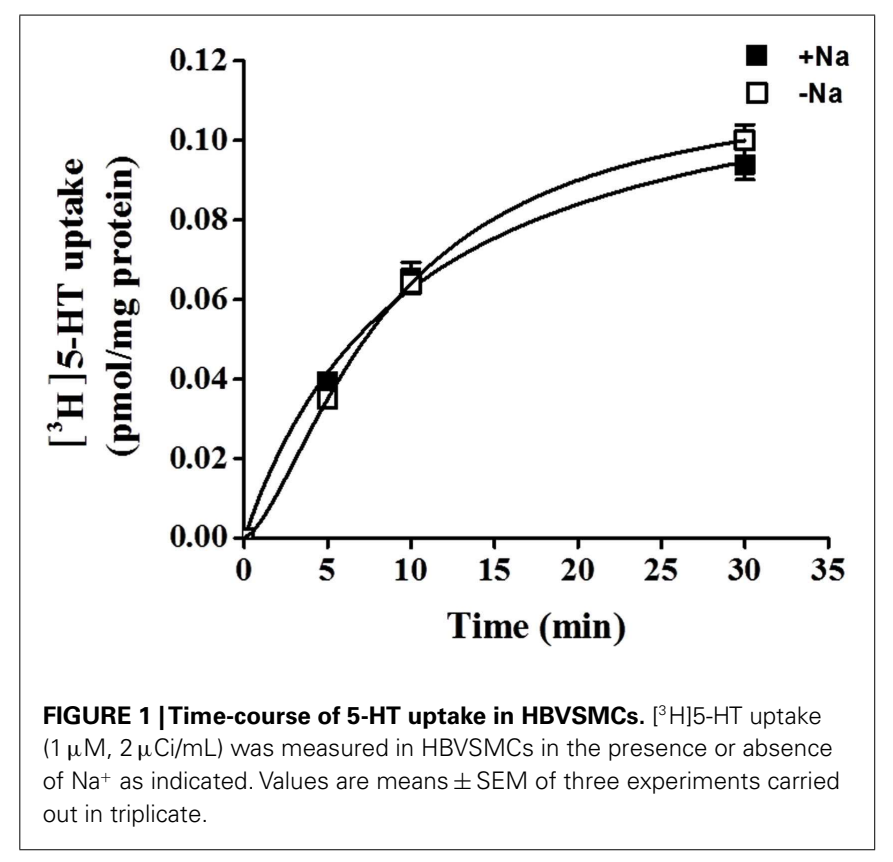

$10.49 \pm 5.98$, and $2.80 \pm 1.04 \mu \mathrm{M}$, respectively (Figure 3 ). The $\mathrm{IC}_{50}$ value for citalopram was significantly different from the that for GBR12935 $(P<0.05)$ but not for desipramine. The $\mathrm{IC}_{50}$ values for desipramine and GBP12935 were not statistically different. Corticosterone (a specific OCT-3 inhibitor) could only inhibited 5-HT uptake in HBVSMCs by $27 \%$, with the threshold concentration between 10 and $100 \mathrm{nM}$.

\section{IDENTIFICATION OF TRANSPORTERS IN HBVSMCs BY RT-PCR}

Reverse transcription-polymerase chain reaction (RT-PCR) was used to study the mRNA expressions of different transporters in HBVSMCs. cDNA from human livers and kidneys were used 


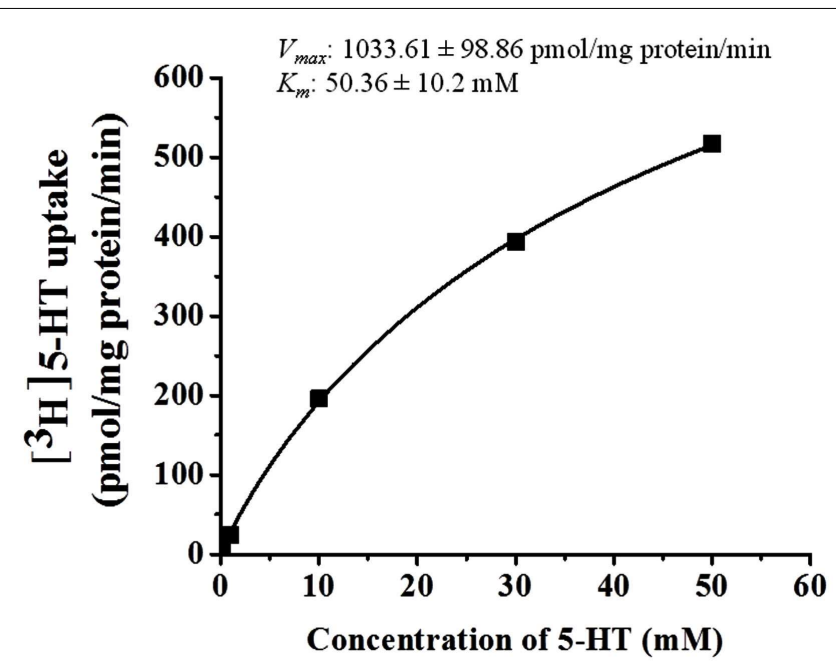

FIGURE 2 | Kinetic analyses of 5-HT uptake in HBVSMCs. Concentration dependence of $5-\mathrm{HT}(0.1 \mu \mathrm{M}$ to $50 \mathrm{mM})$ uptake was determined by measuring $\left[{ }^{3} \mathrm{H}\right] 5-\mathrm{HT}$ uptake at room temperature for $30 \mathrm{~min}$. Values are means \pm SEM of three experiments carried out in triplicate.

as positive controls because all the transporters studied were expressed in these tissues. The PCR products of OCT-3 and PMAT were amplified by RT-PCR from RNA isolated from HBVSMCs (Figure 4). The molecular sizes of PCR products were the same as expected and the PCR products were confirmed by sequencing, indicating the mRNA expressions of OCT-3 and PMAT in HBVSMCs. In contrast, the PCR product of OCT-1, OCT-2, SERT, NET, and DAT were not detected.

\section{SIRNA KNOCKDOWN OF OCT-3 AND PMAT}

Organic cation transporter-3 and PMAT were knocked down specifically using siRNA to verify their contribution to 5-HT transport in HBVSMCs. Transfection of HBVSMCs with siRNA against OCT -3 resulted in a reduction in mRNA and protein expressions of 64.3 and $72.2 \%$, respectively, as well as a reduction in $5-\mathrm{HT}$ uptake of $22.1 \%$ in HBVSMCs. Transfection of HBVSMCs with siRNA against PMAT resulted in a reduction in mRNA and protein expressions of 81.2 and $71.5 \%$, respectively, as well as a reduction in 5-HT uptake of $34.2 \%$ in HBVSMCs (Figure 5).

\section{DISCUSSION}

In the present study, we characterized the 5-HT uptake system in HBVSMCs (i.e., vascular smooth muscle cells cultured from human brain). Similar to the findings in certain vascular beds such as mesenteric arteries, vena cava, and jugular vein (Wanstall et al., 2003; Linder et al., 2008a,b), SERT does not have a significant contribution to 5-HT uptake in HBVSMCs. This conclusion can be supported by the fact that: (i) the mRNA of SERT is not expressed in HBVSMCs; (ii) 5-HT uptake in HBVSMCs is $\mathrm{Na}^{+}$independent; (iii) the apparent affinity of HBVSMCs for 5-HT is much lower than that of SERT $\left(K_{\mathrm{m}}, 1033 \mu \mathrm{M}\right.$ vs. $463 \mathrm{mM}$; Ramamoorthy et al., 1993); and (iv) citalopram at $100 \mathrm{nM}$ (a dose that can inhibit SERT) does not affect 5-HT uptake in HBVSMCs. The lack of SERT activity in HBVSMCs could suggest that different

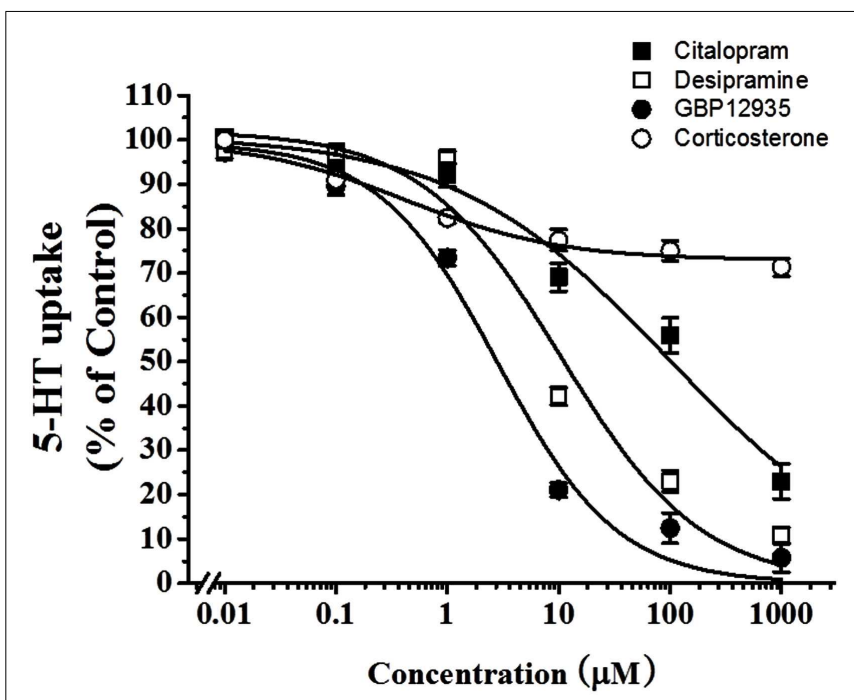

FIGURE 3 | Effects of various transporter inhibitors on 5-HT uptake in HBVSMCs. $\left[{ }^{3} \mathrm{H}\right] 5-\mathrm{HT}$ uptake $(1 \mu \mathrm{M}, 2 \mu \mathrm{Ci} / \mathrm{mL})$ was measured at room temperature for $30 \mathrm{~min}$ in the presence of various concentrations of citalopram ( $\square$ ), desipramine ( $\square$ ), GBR12935 (•), and corticosterone (O). Values are means \pm SEM of three experiments carried out in triplicate.

mechanisms may be responsible for 5-HT uptake in different vascular beds.

It has been reported that $5-\mathrm{HT}$ is one of the substrates of NET and DAT (Daws et al., 1998; Zhou et al., 2002). However, the present study has shown that the mRNA of NET and DAT are not expressed in HBVSMCs. BGR12935 and desipramine, which block DAT and NET in the nanomolar range, inhibited 5-HT uptake in HBVSMCs only at micromolar concentrations. Therefore, the involvement of NET and DAT in 5-HT uptake in HBVSMCs can be excluded. More likely candidates responsible for non-SERTdependent 5-HT uptake in HBVSMCs are OCTs. OCTs are electrogenic and $\mathrm{Na}^{+}$-independent transporters (Koepsell et al., 2007). Substrates for OCTs can be as diverse as 5-HT, dopamine, norepinephrine, epinephrine, histamine, and cimetidine (Jonker and Schinkel, 2004). Three OCT isoforms, which share high sequence homologies and a common 12-transmembrane domain structure, have been identified and characterized from human and other mammalian species. They display considerable overlap in substrate specificity and are differentially expressed in various tissues. OCT-1 and OCT-2 are mainly expressed in the liver and kidney, respectively, where they are supposed to play a key part in systemic elimination of organic cations (Gorboulev et al., 1997; Zhang et al., 1997; Wright and Dantzler, 2004). OCT-3 (also called "extraneuronal monoamine transporter") has a broad distribution and is found in the liver, heart, placenta, skeletal muscle, kidney, and brain (Gründemann et al., 1998; Wu et al., 2000). The results of RT-PCR in the present study revealed that the mRNA of OCT-3 (but not OCT-1 and OCT-2) is expressed in HBVSMCs. From a pharmacological perspective, OCT-3 can be distinguished from the SERT, DAT, NET, and other isoforms of OCTs by inhibition by corticosterone, $O$-methyl isoprenaline, and levamisole (Horvath et al., 2003; Martel and Azevedo, 2003). 
A
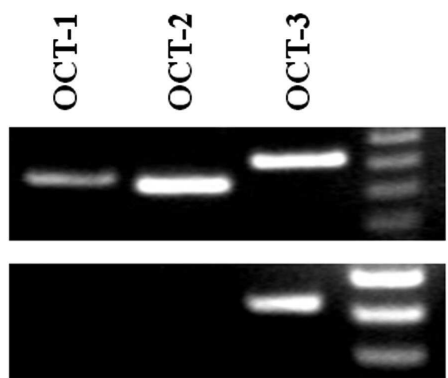

C

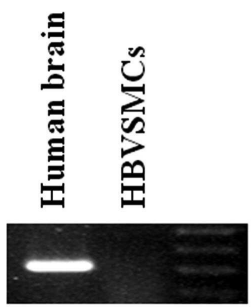

D

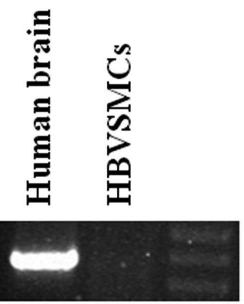

B

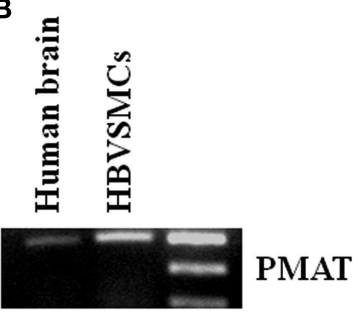

E

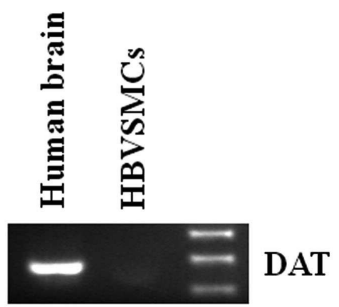

FIGURE 4 | Reverse transcription-polymerase chain reaction analyses of various 5-HT transporter mRNAs in HBVSMCs. PCR products are seen in reactions using oligonucleotide primer pairs for (A) OCT-3 and (B) PMAT but not for (A) OCT-1, OCT-2, (C) SERT, (D)
NET, and (E) DAT. Positive controls with human liver or brain cDNA indicate the expected sizes of amplified fragments: $363 \mathrm{bp}$ (OCT-1), $334 \mathrm{bp}$ (OCT-2), $419 \mathrm{bp}$ (OCT-3), $319 \mathrm{bp}$ (SERT), 400 bp (PMAT), $395 \mathrm{bp}$ (NET), and $370 \mathrm{bp}$ (DAT).
A

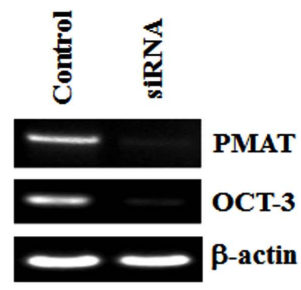

B

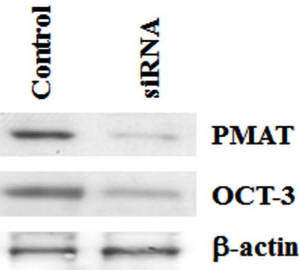

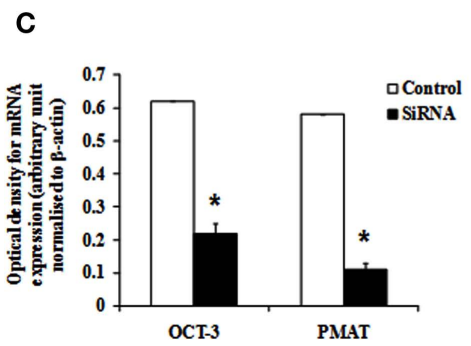

D

E
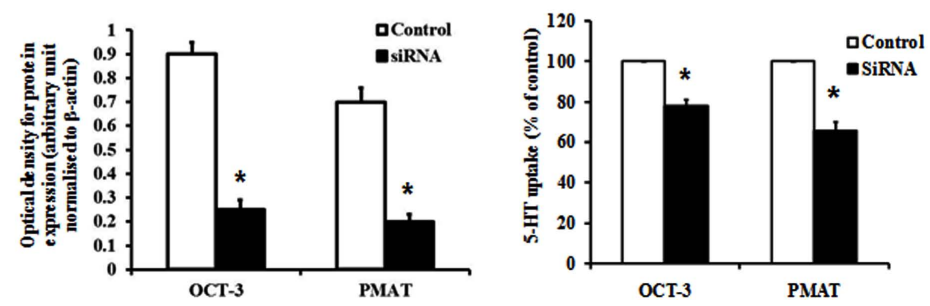

FIGURE 5 | Effects of siRNA knockdown of OCT-3 and PMAT on 5-HT uptake in HBVSMCs. (A) mRNA and (B) protein expressions of OCT-3 and PMAT mRNA in HBVSMCs transfected with siRNA against OCT-3 and PMAT and a control non-silencing sequence. Bar graph showing the amount of (C)
mRNA and (D) protein of OCT-3 and PMAT normalized to $\beta$-actin. (E) 5-HT uptake in HBVSMCs transfected with OCT-3 and PMAT siRNA and a control non-silencing sequence. Values are means \pm SEM of three separate experiments. ${ }^{*} P<0.05$ vs. control.
In the present study, corticosterone inhibited uptake of 5-HT by $27 \%$ and the threshold concentration was found between 10 and $100 \mathrm{nM}$, which is consistent to the characteristics of OCT-3 $\left(\mathrm{IC}_{50}=0.29 \mu \mathrm{M}\right.$; Hayer-Zillgen et al., 2002). Furthermore, siRNA knockdown of OCT-3 resulted in an inhibition of 5-HT uptake of $22 \%$ in HBVSMCs. All these data imply that OCT-3 may be involved in 5-HT uptake in HBVSMCs. However, the inability of corticosterone and siRNA against OCT-3 to abolish 5-HT uptake in HBVSMCs indicates the existence of other 5-HT transport systems in these cells. 
Plasma membrane monoamine transporter shows homology to the equilibrative nucleoside transporter family but, unlike the existing equilibrative nucleoside transporter members that mainly transport nucleosides, PMAT specifically transports biogenic amines such as 5-HT and dopamine (Engel et al., 2004). The present study shows that the mRNA of PMAT is expressed in HBVSMCs. Also, the characteristic of 5-HT uptake activity in HBVSMCs, such as $\mathrm{Na}^{+}$independence, low-affinity for 5HT, and sensitivity to inhibitors of DAT, SERT, and NET in the micromolar range, coincide well with the properties of PMAT (Engel et al., 2004). Therefore, we cannot exclude the possibility that PMAT may also have a significant role in 5-HT uptake in HBVSMCs. A good pharmacological inhibitor for PMAT is currently unavailable. Although decynium-22 is a strong inhibitor of PMAT $\left(K_{\mathrm{i}}=0.1 \mu \mathrm{M}\right.$; Engel and Wang, 2005), it can inhibit OCT-3 with the same potency (Hayer-Zillgen et al., 2002). An alternative method to study PMAT is the use of siRNA. In the present study, 5-HT uptake was reduced by $34 \%$ after the siRNA knockdown of PMAT. This indicates that PMAT contributes to 5-HT uptake in HBVSMCs.

Other unidentified transporters or mechanisms independent of protein transporters may be involved in 5-HT uptake. 5$\mathrm{HT}_{2 \mathrm{~A}}$ receptors on the cell membrane can be internalized upon stimulation by 5-HT (Bhattacharyya et al., 2002; Gray et al., 2003). However, it is hitherto unclear if the internalization of 5-HT receptors is involved in 5-HT uptake, just like the well-known ability of the endothelin type $\mathrm{B}$ receptor to act as a clearance receptor for endothelin-1 (Fukuroda et al., 1994). Also, 5-HT is a very small molecule that can alternate its charge dependent upon $\mathrm{pH}$. 5-HT may be able to cross the plasma membrane by passive diffusion. Nevertheless, based on the observation that pharmacological blockers and siRNA could greatly inhibit the 5-HT uptake in HBVSMCs, the involvement of transporter-independent mechanisms should not be significant.

The role of 5-HT in hypertension is controversial and intriguing. The enhancement of potency for 5-HT in inducing vasoconstriction or the pressor response have been observed in several models of hypertension, including DOCA-salt hypertensive rats (Watts, 1998), spontaneous hypertensive rats (Collis and Vanhoutte, 1981), and in human patients (Golino et al., 1991). Many mechanisms may contribute to this hyper-responsiveness, such as changes in 5-HT receptor signaling or changing circulating levels of 5-HT. It has been reported that the expression and function of $5-\mathrm{HT}_{2}$ receptors are up-regulated in arterial smooth muscle in DOCA-salt hypertensive rats (Watts, 2002; Banes and Watts, 2003). In addition, SERT function in the aortas of DOCA-salt and

\section{REFERENCES}

Amenta, F., De Rossi, M., Mione, M. C., and Geppetti, P. (1985). Characterization of $[3 \mathrm{H}] 5$-hydroxytryptamine uptake within rat cerebrovascular tree. Eur. J. Pharmacol. 112, 181-186. Baganz, N. L., Horton, R. E., Calderon, A. S., Owens, W. A., Munn, J. L., Watts, L. T., et al. (2008).
Organic cation transporter 3: keeping the brake on extracellular serotonin in serotonin-transporterdeficient mice. Proc. Natl. Acad. Sci. U.S.A. 105, 18976-18981.

Banes, A. K., and Watts, S. W. (2003). Arterial expression of 5HT2B and 5-HT1B receptors during development of DOCA-salt

LNNA-hypertensive rats is impaired (Ni et al., 2006). It may lead to an increase in the level of free-circulating 5-HT. However, the effect of the SERT on blood pressure is controversial because the systolic blood pressure, circadian rhythms in the heart rate and the gross level of motor activity of SERT-knockout rats are not different from those of normal rats (Homberg et al., 2006; Linder et al., 2008a). Such a discrepancy could be because 5-HT is taken up into arteries through mechanisms that are partially (but not completely) dependent upon the SERT, such as OCT-3 and PMAT as shown in the present study. The ability of OCT-3 to transport 5-HT has been demonstrated in SERT-deficient mice (Bengel et al., 1998; Schmitt et al., 2003). More importantly, animals may adapt to the genetic alteration. Activated or up-regulated mechanisms may serve the function of the ablated gene. It has been reported that OCT-3 contributes to 5-HT clearance if the expression of the SERT is low or absent. For instance, mRNA expression of OCT-3 is significantly increased in the intestine and hippocampus of SERT-deficient mice (Chen et al., 2001; Schmitt et al., 2003; Baganz et al., 2008). Therefore, OCT-3 may be important in the homeostatic regulation of extracellular 5-HT levels by ensuring (albeit low-affinity) uptake of 5-HT, particularly in the face of constitutively reduced expression or function of the SERT such as that seen in hypertension or during treatment with selective serotonin re-uptake inhibitors (Hirano et al., 2005; Mirza et al., 2007). The regulation of PMAT in SERT-knockout animals is not known. Investigating the possibility that chronic inactivation of the SERT also leads to compensatory up-regulation of PMAT will be interesting.

In conclusion, we demonstrated that 5-HT uptake in HBVSMCs is mediated predominantly by a low-affinity, $\mathrm{Na}^{+}$independent, and $\mathrm{pH}$-dependent mechanism. The most possible candidates are OCT-3 and PMAT. Unlike previous findings in the aorta, the SERT does not participate in 5-HT uptake in HBVSMCs. We hypothesize that OCT-3 and PMAT may have a role in regulating 5-HT functions by controlling the local concentration of 5 - $\mathrm{HT}$ in the vicinity of $5-\mathrm{HT}_{2}$ receptors in vascular smooth muscle cells. It is worth studying if impairment of OCT-3 and PMAT may be related to vascular diseases such as hypertension, ischemic stroke, arteriosclerosis, or even Alzheimer's disease because this disease is not only a neurological but also a cerebrovascular disorder.

\section{ACKNOWLEDGMENTS}

This work was supported by the RGC General Research Fund of Hong Kong SAR (project code: 769607), and the Seed Funding for Basic Research Program of the University of Hong Kong (project code: 200807176070).

hypertension. BMC Pharmacol.3:12. doi:10.1186/1471-2210-3-12

Bengel, D., Murphy, D. L., Andrews, A. M., Wichems, C. H., Feltner, D., Heils, A., et al. (1998). Altered brain serotonin homeostasis and locomotor insensitivity to 3,4 methylenedioxymethamphetamine ("Ecstasy") in serotonin transporter-deficient mice. Mol. Pharmacol. 53, 649-655.

Bhattacharyya, S., Puri, S., Miledi, R., and Panicker, M. M. (2002). Internalization and recycling of 5-HT2A receptors activated by serotonin and protein kinase C-mediated mechanisms. Proc. Natl. Acad. Sci. U.S.A. 99, 14470-14475. 
Chen, J. J., Li, Z., Pan, H., Murphy, D. L., Tamir, H., Koepsell, H., et al. (2001). Maintenance of serotonin in the intestinal mucosa and ganglia of mice that lack the high-affinity serotonin transporter: abnormal intestinal motility and the expression of cation transporters. J. Neurosci. 21, 6348-6361.

Collis, M. G., and Vanhoutte, P. M. (1981). Tachyphylaxis to 5hydroxytryptamine in perfused kidneys from spontaneously hypertensive and normotensive rats. J. Cardiovasc. Pharmacol. 3, 229-235.

Daws, L. C., Toney, G. M., Gerhardt, G. A., and Frazer, A. (1998). In vivo chronoamperometric measures of extracellular serotonin clearance in rat dorsal hippocampus: contributions of serotonin and norepinephrine transporters. J. Pharmacol. Exp. Ther. 286, 967-976.

Dohi, Y., and Lüscher, T. F. (1991). Altered intra- and extraluminal effects of 5-hydroxytryptamine in hypertensive mesenteric resistance arteries: contribution of the endothelium and smooth muscle. J. Cardiovasc. Pharmacol. 18, 278-284.

Eddahibi, S., Fabre, V., Boni, C., Martres, M. P., Raffestin, B., Hamon, M., et al. (1999). Induction of serotonin transporter by hypoxia in pulmonary vascular smooth muscle cells. Relationship with the mitogenic action of serotonin. Circ. Res. 84, 329-336.

Eddahibi, S., Humbert, M., Fadel, E., Raffestin, B., Darmon, M., Capron, F., et al. (2001). Serotonin transporter overexpression is responsible for pulmonary artery smooth muscle hyperplasia in primary pulmonary hypertension. J. Clin. Invest. 108, 1141-1150.

Engel, K., and Wang, J. (2005). Interaction of organic cations with a newly identified plasma membrane monoamine transporter. Mol. Pharmacol. 68, 1397-1407.

Engel, K., Zhou, M., and Wang, J. (2004). Identification and characterization of a novel monoamine transporter in the human brain. J. Biol. Chem. 279, 50042-50049.

Fukuroda, T., Fujikawa, T., Ozaki, S., Ishikawa, K., Yano, M., and Nishikibe, M. (1994). Clearance of circulating endothelin-1 by ETB receptors in rats. Biochem. Biophys. Res. Commun. 199, 1461-1465.

Golino, P., Piscione, F., Willerson, J. T., Cappelli-Bigazzi, M., Focaccio, A., Villari, B., et al. (1991). Divergent effects of serotonin on coronary-artery dimensions and blood flow in patients with coronary atherosclerosis and control patients. N. Engl. J. Med. 324, 641-648.

Gorboulev, V., Ulzheimer, J. C., Akhoundova, A., Ulzheimer-Teuber, I., Karbach, U., Quester, S., et al. (1997). Cloning and characterization of two human polyspecific organic cation transporters. DNA Cell Biol. 16, 871-881.

Gray, J. A., Bhatnagar, A., Gurevich, V. V., and Roth, B. L. (2003). The interaction of a constitutively active arrestin with the arrestin-insensitive 5-HT2A receptor induces agonistindependent internalization. Mol. Pharmacol. 63, 961-972.

Gründemann, D., Schechinger, B., Rappold, G. A., and Schömig, E. (1998). Molecular identification of the corticosterone-sensitive extraneuronal catecholamine transporter. Nat. Neurosci. 1, 349-351.

Hayer-Zillgen, M., Brüss, M., and Bönisch, H. (2002). Expression and pharmacological profile of the human organic cation transporters hOCT1, hOCT2 and hOCT3. Br. J. Pharmacol. 136, 829-836.

Hirano, K., Seki, T., Sakai, N., Kato, Y., Hashimoto, H., Uchida, S., et al. (2005). Effects of continuous administration of paroxetine on ligand binding site and expression of serotonin transporter protein in mouse brain. Brain Res. 1053, 154-161.

Homberg, J., Mudde, J., Braam, B., Ellenbroek, B., Cuppen, E., and Joles, J. A. (2006). Blood pressure in mutant rats lacking the 5-hydroxytryptamine transporter. Hypertension 48, E115-E116.

Horvath, G., Sutto, Z., Torbati, A., Conner, G. E., Salathe, M., and Wanner, A. (2003). Norepinephrine transport by the extraneuronal monoamine transporter in human bronchial arterial smooth muscle cells. Am. J. Physiol. Lung Cell. Mol. Physiol. 285, L829-L837.

Hutri-Kähönen, N., Kähönen, M., Wu, X., Sand, J., Nordback, I., Taurio, J., et al. (1999). Control of vascular tone in isolated mesenteric arterial segments from hypertensive patients. Br. J. Pharmacol. 127, 1735-1743.

Jonker, J. W., and Schinkel, A. H. (2004). Pharmacological and physiological functions of the polyspecific organic cation transporters: OCT1, 2, and 3 (SLC22A1-3). J. Pharmacol. Exp. Ther. 308, 2-9.

Koepsell, H., Lips, K., and Volk, C. (2007). Polyspecific organic cation transporters: structure, function, physiological roles, and biopharmaceutical implications. Pharm. Res. 24, 1227-1251.
Krygicz, D., Azzadin, A., Pawlak, R. Malyszko, J. S., Pawlak, D., Mysliwiec, M., et al. (1996). Cyclosporine A affects serotonergic mechanisms in uremic rats. Pol. J. Pharmacol. 48, 351-354.

Lee, S. L., Wang, W. W., Moore, B. J., and Fanburg, B. L. (1991). Dual effect of serotonin on growth of bovine pulmonary artery smooth muscle cells in culture. Circ. Res. 68, 1362-1368.

Linder, A. E., Diaz, J., Ni, W., Szasz, T., Burnett, R., and Watts, S. W. (2008a). Vascular reactivity, 5-HT uptake, and blood pressure in the serotonin transporter knockout rat. Am. J. Physiol. Heart Circ. Physiol. 294, H1745-H1752.

Linder, A. E., Ni, W., Szasz, T., Burnett, R., Diaz, J., Geddes, T. J., et al. (2008b). A serotonergic system in veins: serotonin transporterindependent uptake. J. Pharmacol. Exp. Ther. 325, 714-722.

Martel, F., and Azevedo, I. (2003). An update on the extraneuronal monoamine transporter (EMT): characteristics, distribution and regulation. Curr. Drug Metab. 4, 313-318.

Martel, F., Monteiro, R., and Lemos, C. (2003). Uptake of serotonin at the apical and basolateral membranes of human intestinal epithelial (Caco-2) cells occurs through the neuronal serotonin transporter (SERT). J. Pharmacol. Exp. Ther. 306, 355-362.

Mirza, N. R., Nielsen, E. Ø., and Troelsen, K. B. (2007). Serotonin transporter density and anxiolyticlike effects of antidepressants in mice. Prog. Neuropsychopharmacol. Biol. Psychiatry 31, 858-866.

$\mathrm{Ni}$, W., Lookingland, K., and Watts, S. W. (2006). Arterial 5-hydroxytryptamine transporter function is impaired in deoxycorticosterone acetate and Nomega-nitro-L-arginine but not spontaneously hypertensive rats. Hypertension 48, 134-140.

Ni, W., Thompson, J. M., Northcott, C. A., Lookingland, K., and Watts, S. W. (2004). The serotonin transporter is present and functional in peripheral arterial smooth muscle. $J$. Cardiovasc. Pharmacol. 43, 770-781.

Nishimura, Y. (1996). Characterization of 5-hydroxytryptamine receptors mediating contractions in basilar arteries from stroke-prone spontaneously hypertensive rats. $\mathrm{Br}$. J. Pharmacol. 117, 1325-1333.

Parsons, A. A. (1991). 5-HT receptors in human and animal cerebrovasculature. Trends Pharmacol. Sci. 12, 310-315.
Ramamoorthy, S., Bauman, A. L., Moore, K. R., Han, H., YangFeng, T., Chang, A. S., et al. (1993). Antidepressant- and cocaine-sensitive human serotonin transporter: molecular cloning, expression, and chromosomal localization. Proc. Natl. Acad. Sci. U.S.A. 90, 2542-2546.

Schmitt, A., Mössner, R., Gossmann, A., Fischer, I. G., Gorboulev, V., Murphy, D. L., et al. (2003). Organic cation transporter capable of transporting serotonin is up-regulated in serotonin transporter-deficient mice. $J$. Neurosci. Res. 71, 701-709.

Soares-da-Silva, P., Pestana, M., VieiraCoelho, M. A., Fernandes, M. H., and Albino-Teixeira, A. (1995). Assessment of renal dopaminergic system activity in the nitric oxide-deprived hypertensive rat model. Br. J. Pharmacol. 114, 1403-1413.

Tahara, H., Kusuhara, H., Chida, M., Fuse, E., and Sugiyama, Y. (2006). Is the monkey an appropriate animal model to examine drug-drug interactions involving renal clearance? Effect of probenecid on the renal elimination of $\mathrm{H} 2$ receptor antagonists. J. Pharmacol. Exp. Ther. 316, 1187-1194.

Vanhoutte, P. M. (1990). Serotonergic antagonists and vascular disease. Cardiovasc. Drugs Ther. 4(Suppl. 1), 7-12.

Wanstall, J. C., Fiore, S. A., Gambino, A., and Chess-Williams, R. (2003). Potentiation of 5hydroxytryptamine (5-HT) responses by a 5-HT uptake inhibitor in pulmonary and systemic vessels: effects of exposing rats to hypoxia. Naunyn Schmiedebergs Arch. Pharmacol. 368, 520-527.

Watts, S. W. (1998). The development of enhanced arterial serotonergic hyperresponsiveness in mineralocorticoid hypertension. J. Hypertens. 16, 811-822.

Watts, S. W. (2002). Serotonin-induced contraction in mesenteric resistance arteries: signaling and changes in deoxycorticosterone acetate-salt hypertension. Hypertension 39, 825-829.

Wright, S. H., and Dantzler, W. H. (2004). Molecular and cellular physiology of renal organic cation and anion transport. Physiol. Rev. 84 987-1049.

Wu, X., Huang, W., Ganapathy, M. E., Wang, H., Kekuda, R., Conway, S. J., et al. (2000). Structure, function, and regional distribution of the organic cation transporter OCT3 in the kidney. Am. J. Physiol. Renal Physiol. 279, F449-F458. 
Wyse, D. G. (1984). Relationship of blood pressure to the responsiveness of an isolated human artery to selected agonists and to electrical stimulation. J. Cardiovasc. Pharmacol. 6, 1083-1091.

Zhang, L., Dresser, M. J., Gray, A. T., Yost, S. C., Terashita, S., and Giacomini, K. M. (1997). Cloning and functional expression of a human liver organic cation transporter. Mol. Pharmacol. 51, 913-921.

Zhang, S., Lovejoy, K. S., Shima, J. E., Lagpacan, L. L., Shu, Y., Lapuk, A., et al. (2006). Organic cation transporters are determinants of oxaliplatin cytotoxicity. Cancer Res. 66, 8847-8857.

Zhou, F. C., Lesch, K. P., and Murphy, D. L. (2002). Serotonin uptake into dopamine neurons via dopamine transporters: a compensatory alternative. Brain Res. 942, 109-119.

Conflict of Interest Statement: The authors declare that the research was conducted in the absence of any commercial or financial relationships that could be construed as a potential conflict of interest.

Received: 16 November 2012; accepted: 25 January 2013; published online: 12 February 2013.

Citation: Li RWS, Yang C, Kwan YW, Chan SW, Lee SMY and Leung GPH (2013) Involvement of organic cation transporter-3 and plasma membrane monoamine transporter in serotonin uptake in human brain vascular smooth muscle cells. Front. Pharmacol. 4:14. doi 10.3389/fphar.2013.00014
This article was submitted to Frontier in Cardiovascular and Smooth Muscle Pharmacology, a specialty of Frontiers in Pharmacology.

Copyright (c) 2013 Li, Yang, Kwan, Chan, Lee and Leung. This is an openaccess article distributed under the terms of the Creative Commons Attribution License, which permits use, distribution and reproduction in other forums, provided the original authors and source are credited and subject to any copyright notices concerning any third-party graphics etc. 